DR INGRID BRETHERTON (Orcid ID : 0000-0002-7158-8804)

DR MATHIS GROSSMANN (Orcid ID : 0000-0001-8261-3457)

DR ADA S CHEUNG (Orcid ID : 0000-0001-5257-5525)

Article type : 3 Original Article - Australia, Japan, SE Asia

\title{
Australian Endocrinologists need more training in transgender health: a national survey
}

Ingrid Bretherton ${ }^{1,2}$, Mathis Grossmann ${ }^{1,2}$, Shalem Y. Leemaqz ${ }^{3}$, Jeffrey D. Zajac ${ }^{1,2}$, Ada S. Cheung ${ }^{1,2}$

${ }^{1}$ Department of Endocrinology, Austin Health, Heidelberg, Victoria, Australia ${ }^{2}$ Department of Medicine (Austin Health), The University of Melbourne, Victoria, Australia ${ }^{3}$ Robinson Research Institute, Adelaide Medical School, The University of Adelaide, South Australia.

Correspondence: Dr Ingrid Bretherton, Austin Health, 145 Studley Road, Heidelberg,

Victoria 3084, Australia. Tel +613 9496 5489; Fax +613 9496 2980; Email:

ibretherton@student.unimelb.edu.au

Acknowledgments: We acknowledge the participants who took part in this study

Conflict of Interest: The authors have no conflicts to declare.

Funding Statement: Ingrid Bretherton is supported by an Australian Government Research Training Program Scholarship and a Rowden White Scholarship (application ref: 184409), The University of Melbourne. Ada Cheung is supported by an Australian Government This is the author manuscript accepted for publication and has undergone full peer review but has not been through the copyediting, typesetting, pagination and proofreading process, which may lead to differences between this version and the Version of Record. Please cite this article as doi: $10.1111 / C E N .14143$

This article is protected by copyright. All rights reserved 
National Health and Medical Research Council Early Career Fellowship (\#1143333) and receives research support from the Viertel Charitable Foundation Clinical Investigator Award, Endocrine Society of Australia Postdoctoral Award and the Royal Australasian College of Physicians Vincent Fairfax Family Foundation.

Data Availability Statement: The data that support the findings of this study are available from the corresponding author upon reasonable request.

Summary:

Objective: An increasing number of trans and gender diverse (TGD) individuals are seeking gender-affirming hormone therapy for gender transition. Little is known about the levels of training, experience and confidence of Endocrinologists in providing care and lack of training and experience is a potential barrier to individuals seeking appropriate and timely healthcare. We aimed to assess the level of training and confidence of Australian endocrinologists and trainees in the endocrine management of trans and gender diverse individuals in a representative sample.

Design: Endocrinologist and trainee members of the Endocrine Society of Australia were invited to participate in an anonymous 14-item survey. Of the 545 members, 147 clinicians (95 adult endocrinologists, 2 paediatric endocrinologists and 50 endocrinology trainees) responded.

Results: When presented with a scenario regarding commencement of gender-affirming hormone therapy only $19 \%$ felt confident providing clinical care to TGD individuals. Compared to other areas of endocrinology $75 \%$ felt less or not at all confident in commencing hormone therapy in a TGD patient. No training in transgender medicine during medical school or during their endocrinology training was reported by $96 \%$ and $60 \%$ respectively. There were significantly higher levels of confidence in all aspects including performing a consultation in those who had previously seen a TGD patient. The desire for more training was high (91\%).

Conclusions: These results highlight the shortfall in training in TGD healthcare amongst endocrinologists and show that prior clinical experience is associated with higher levels of confidence. Medical schools and endocrinology fellowship training programs will need to adapt to meet the increasing demand for quality TGD health services. 
Key Words: Transgender, gender diverse, survey, Australia, endocrinologist, trainees, training, education

\section{i) MAIN TEXT}

\section{INTRODUCTION}

Transgender (trans) including those who identify as gender diverse (TGD) is an umbrella terms for people whose gender identity or gender expression is different from what is typically associated with their sex assigned at birth ${ }^{1}$. There is increasing recognition that gender exists on a spectrum rather than a male/female binary. Gender-affirming hormone therapy (formerly referred to as cross-sex hormone therapy) is used to align a person's physical characteristics with their gender identity. The goal is to alleviate gender dysphoria, the distress many TGD individuals experience when their gender identity is markedly and persistently incongruent from their birth assigned sex ${ }^{2}$. An estimated $0.6 \%-1.2 \%$ of the population identifies as TGD ${ }^{3-5}$ and there is increasing demand for trans and gender diverse healthcare in Australia ${ }^{6,7}$.

Between $56-75 \%$ of transgender individuals have clinically diagnosed depression, and $48 \%$ have attempted suicide; rates far higher than the general population ${ }^{7-10}$. Timely access to hormone therapies is associated with better psychological functioning and less anxiety, depression and gender dysphoria ${ }^{11-13}$. Typically, feminization is achieved with estradiol as well as suppression of endogenous sex hormones with gonadotropin releasing hormone analogues or anti-androgen agents. Testosterone is used to promote masculinisation. Endocrinologists have experience in prescribing hormone therapy and therefore often oversee this process. There are international transgender health guidelines to guide prescribing practitioners 1,14 and the importance of gender-affirming hormone therapy is acknowledged by Endocrine societies worldwide 11,12,15.

Despite this, significant barriers exist in TGD healthcare. A 2010 United States (US) study revealed 19\% TGD individuals reported being refused medical care due to their transgender or gender non-conforming status ${ }^{16}$ and a subsequent US survey involving 350 TGD people reported that $31 \%$ needed, but were not receiving, hormone therapy ${ }^{17}$. A 2015 survey of an Australian gender service found that the most commonly cited negative aspect of the clinic 
was the long waiting time to receive an appointment. ${ }^{13}$

Inability to find doctors who will provide gender-affirming care is a major concern for the TGD community ${ }^{17,18}$. This may stem from inadequate training as international studies show that adequacy of training of endocrinologists in managing TGD individuals is lacking. ${ }^{19-21}$

Assessing levels of training and confidence of doctors is important to guide change and this has so far never been assessed in the Australian context. We therefore aimed to assess the amount of training and confidence of Endocrinologists and advanced trainees in providing gender-affirming hormone therapy. We hypothesized that Australian endocrinologists receive insufficient training in TGD care and that there is a desire for further education. Given the increasing demand for transgender health services, we intend to use data collected to contribute to evidenced-based improvements in the design of training resources and ultimately improve health service provision for the TGD community.

\section{METHODS}

This anonymous 14-item online survey of training needs in transgender health was developed by four clinical endocrinologists with expertise in this area. Authors drew from other relevant published studies when designing this survey ${ }^{20,22}$. The survey was open to Australian endocrinologists and endocrine advanced trainees between $1^{\text {st }}$ June 2017 to $31^{\text {st }}$ December 2017. The survey preamble and questions are included in full in Appendix 1.

All clinical members of the Endocrine Society of Australia, the main professional body for practicing endocrinologists, (451 endocrinologists and 94 advanced trainees) were invited to complete the survey via a link to an online survey platform provider (SurveyMonkey). The survey was advertised via email in the Endocrine Society of Australia member bulletin, and to attendees at an endocrine advanced trainee lecture series.

Univariate analysis using Cochran-Armitage test was used to compare the level of confidence in managing TGD individuals between Endocrinologists who had seen a TGD individual to those who had not, and between Endocrinologists who had read the Endocrine Society guidelines to those who had not. 
The study was approved by the Austin Health Human Research Ethics Committee (HREC/17/Austin/372).

Demographics

Demographic data of respondents were obtained, including gender, age range, state or territory of practice, type of endocrine specialist (adult, paediatric, trainee, other), and main place of practice (tertiary hospital, non-tertiary hospital, private clinic, or other). Case load (number of transgender patients currently treating) and experience (number of transgender individuals even treated) was also obtained.

\section{Level of confidence}

Participants were provided with a straightforward scenario to ascertain if they would be willing to prescribe hormone treatment for an individual with confirmed gender dysphoria (see Appendix 1). Clinicians were then asked to rate their level of confidence in undertaking a consultation with a TGD individual, including taking a history, as well as prescribing and monitoring gender- affirming hormone therapy (please note this was formerly known as cross-sex hormone therapy, which was the terminology used in the survey but has since been superseded based on community feedback and will be referred to as gender-affirming hormone therapy in this discussion) compared with other areas of endocrinology.

\section{Training and experience}

Prior training (as a medical student, advanced trainee or as a qualified endocrinologist) in transgender health was quantified. Respondents were asked to self-rate the amount of training they had received (too much, adequate, not enough) and whether there was a desire for further training (yes, no, unsure). Knowledge of existing published international transgender care guidelines was assessed.

\section{RESULTS}

Of 545 clinical Endocrine Society of Australia members, there was a total of 149 respondents $(27.3 \%)$. Two were excluded as they were neither endocrinologists nor trainees ( 1 nurse practitioner, 1 general physician). The remaining 147 respondents included 95 adult endocrinologists, 2 paediatric endocrinologists and 50 endocrinology advanced trainees. Results are summarized in tables 1, 2 and 3. 


\section{Demographics}

The responders were broadly representative of the gender ratio of Endocrine Society of Australia members (34\% of responders identified as male and $66 \%$ as female. No participants selected the other/free text gender option). The majority of participants (52\%) were ages 3039 years. The majority of responses came from the South Eastern States and the majority worked in a tertiary hospital setting (75\%). With regards to clinical experience, $14 \%$ had never seen a TGD individual in clinical practice, and only 65\% had no TGD individuals

currently under their care. Demographic data of the respondents are shown in Table 1.

\section{Level of confidence}

When presented with a straightforward scenario of a patient formally diagnosed with gender dysphoria by a psychiatrist and referred by their GP for commencement of hormone therapy, $54 \%$ did not feel confident prescribing hormone therapy and opted to refer to a colleague or gender service. Only 19\% felt comfortable treating. The large majority (75\%) felt less confident or not at all confident in commencing hormone therapy in a TGD patient compared to other areas of endocrinology. On the other hand, almost half (46\%) felt reasonably or more confident in performing a history. Data are summarized in table 2.

To determine whether any previous clinical experience with transgender individuals is associated with a higher level of confidence, Cochran-Armitage test was conducted to compare the confidence levels of practitioners who had seen one or more transgender patient compared to those who had seen none. There was a statistically significant difference in all aspects including performing a consultation, history taking, commencing hormone therapy and monitoring of hormone therapy with higher levels of confidence in those who had previously seen a TGD patient $(\mathrm{p}<0.0001)$. Additionally, there was a significantly higher level of confidence in all areas in those who had previously read the Endocrine society guidelines in this area $(\mathrm{P}<0.0001)$ (see Appendix 2).

\section{Training and experience}

A very low proportion (1\%) reported having received had any training in transgender health as a medical student. In addition, 36\% reported receiving training in transgender health during their endocrinology advanced training and 29\% received some training since 
qualifying as an endocrinologist. Overall, $88 \%$ believed there was not enough training in transgender medicine and 91\% desired more training. Over half (53.7\%) had never read international guidelines. Data are summarized in table 3.

\section{DISCUSSION}

This is the only study to assess adequacy of training of endocrinologists in managing TGD individuals in Australia, and more specifically, to assess if the clinical experience of having seen a TGD patient or reading clinical guidelines was associated with higher clinician confidence in providing gender-affirming care. In this national survey involving 147 adult endocrinologists and trainees, we found that firstly, clinicians lacked confidence when prescribing and monitoring hormone therapy; secondly, there was a widespread lack of training in transgender medicine from student to postgraduate levels; and thirdly, endocrinologists desired further education and training. We also demonstrate that clinical experience with one or more TGD patients and familiarity with the US Endocrine Society guidelines were both associated with improved confidence to provide gender-affirming care.

\section{Levels of Confidence}

While our survey differed to those used in other studies, our data suggest that confidence levels of Australian endocrinologists in managing transgender individuals were even lower than their overseas counterparts. A survey of US endocrine conference attendees found that $41 \%$ felt "somewhat" or "very" competent to provide transgender care ${ }^{20}$. This compares to $33 \%$ of people in our study that felt at least reasonably confident compared to other areas of Endocrinology.

In this study, cclinical experience as well as awareness of published guidelines were both associated with higher levels of confidence and should therefore be the target of future educational interventions. It is important to remember that confidence does not always translate to competence. Assessing competence would be important aspect to address in future studies.

Training and experience

Our findings show that less than one in five Australian endocrinologists and trainees who responded felt they had received sufficient training with respect to initiating therapy, and 
more than half preferred to refer TGD individuals to a colleague. The majority (88\%) believed they had not received enough training in transgender medicine but despite this over $85 \%$ have managed at least one TGD patient. These findings are similar to a survey of over 400 US Endocrine Society members, which found that over $80 \%$ had never received training in the care of TGD patients even though almost $80 \%$ had treated a TGD patient ${ }^{19}$. Similarly low levels of training were reported in other specialties relevant to the TGD community such as US plastic surgery and urology residency programs ${ }^{23}$. In this study, only $36 \%$ had ever seen five or more TGD patients at any stage and less than $12 \%$ currently had five or more TGD individuals under their care. Adequate clinical exposure is an important as those who had seen one or more TGD individual also had higher levels of confidence in this area.

A likely explanation for the lack of training in TGD health in medical schools and endocrinology training programs is a delay in these institutions responding to changes in clinical care needs. Although TGD individuals have always been part of our society, the growing awareness and increasing visibility of the community has brought the issues they face to the forefront. Adapting the teaching agenda of medical schools and fellowship programs takes time and there is lag between identifying an area where more education is needed and implementing practical changes to address it. Dubin et al postulate that a lack of well-established best practice guidelines, barriers to implementing any additional material to an already busy medical school curricula and lack of evidence to guide the best way to implement these changes all contribute ${ }^{24}$.

Additionally, a 2017 US survey of endocrinology fellowship program directors revealed there was a perceived a lack of faculty interest or experience in transgender healthcare as well as lack of training resources and lack of funding for this area. ${ }^{19}$ Our findings lend support to the urgent need to address training gaps which could be targeted through expected clinical exposure to TGD patients as part of endocrine training.

Further education

Further training was desired by $91 \%$ of our participants. In addition to implementing changes to medical school curricula, development of a transgender education program specifically targeted to endocrinology trainees could address the specific training and confidence shortfalls uncovered by this study. A 2018 US survey of endocrinology trainees found that lectures from visiting professors was the most preferred method of receiving transgender 
healthcare content. ${ }^{25}$ When asked to rate their comfort level before and after an educational session $73 \%$ of US participants felt a single session improved their comfort level with transgender care and 91\% felt a similar session should be mandatory in endocrinology training programs $\mathrm{s}^{25}$. Other desired methods of education included elective rotations, online training modules, and attendance at meetings ${ }^{25}$.

This study showed higher levels of confidence in those who had some clinical experience in TGD healthcare. There are many avenues for exposure of endocrinologists and endocrine trainees to TGD patients. Establishing dedicated gender clinics are one option which would not only help to address the shortfall in services for TGD individuals but also allow focused training rotations for endocrinology trainees to gain valuable practical experience. ${ }^{25}$ An alternative option to manage the rapidly increasing numbers of TGD people seeking genderaffirming hormone therapy is to consider TGD endocrine care as mainstream endocrinology. Given that management principles with testosterone and estradiol are similar to treatment of hypogonadism from other causes such as menopause, this is a feasible approach.

It is also important to consider that educating all doctors, not just endocrinologists will have far reaching benefits. TGD individuals, like everyone, experience general health concerns. A person's health needs may depend on their anatomy rather than their gender identity, such as cervical screening in TGD people assigned female at birth and prostate screening in TGD people assigned male at birth. Practical changes such as adapting patient registration forms to include gender options beyond the binary, using the person's preferred name and pronoun, as well as availability of appropriate non-gendered toilet facilities are also important ${ }^{26}$.

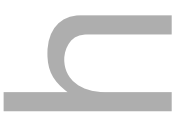

Just over half of current endocrinologists and trainees surveyed had never read the relevant international guidelines and they also had lower levels of confidence in TGD healthcare.

However, international guidelines do not address local differences in practice and availability of specific medications. For example, the antiandrogen agent cyproterone acetate is not approved by the US FDA due to case reports of hepatotoxicity, yet it is widely used in Europe, Australia and elsewhere. Conversely, spironolactone is almost never used as an antiandrogen agent in Europe but is commonly used in US and Australia. This provides an impetus for the development of locally relevant resources and in response to findings from this survey, we have published Australian-based treatment recommendations for gender- 
affirming hormonal therapy ${ }^{27}$.

\section{Limitations}

The sample size was relatively small with $27 \%$ of Endocrine Society of Australia members taking part in this study. However, this is much higher than a similar US study where the response rate was under $6 \%{ }^{19}$ and higher than other comparable studies ${ }^{22}$. Responder bias is a consideration with a predominance responders from the South Eastern states, although the majority of endocrinologists and trainees are based in these areas. There were few participants from Northern Territory, Australian Capital Territory and Tasmania, reflecting the fewer practicing endocrinologists and trainees in these areas. It is postulated that nonresponders may be even less engaged. Nonetheless, our results mirror those identified overseas ${ }^{19-21}$. The survey was advertised at national endocrinology training events, which may explain the large number of responses from advanced trainees. Paediatric Endocrinologists are under-represented in this cohort however the Endocrine Society of Australia is comprised of predominantly adult endocrinologists and trainees.

Implications and future direction

Based on our findings we recommend the following :

1. Incorporation of TGD health into medical school and endocrine training curricula.

Training or lectures delivered should be designed by experienced clinicians in collaboration with TGD community members. Inclusion of community voices allows an understanding of health issues and barriers faced by the TGD community and the importance of respect and affirmation with non-gendered inclusive language, which is as important as the specifics of gender-affirming hormonal therapy.

2. Clinical exposure of all endocrine trainees to TGD patients during their training program.

3. Improved visibility of TGD health and research at professional society conferences and seminars to upskill endocrinologists.

4. Promotion of existing local or international guidelines on the endocrine and related care of TGD people to trainees and endocrinologists.

5. Further research to assess the impact of educational interventions to ensure knowledge, confidence and competence in TGD medicine increases over time.

Conclusions 
Whilst TGD community members express an inability to find doctors willing to provide gender-affirming hormone therapy as a major barrier to healthcare, our study suggests that this may be related to a widespread lack of training and a lack of confidence among Australian endocrinologists and trainees in the provision of gender-affirming hormone therapy. An Australian position statement on the treatment of transgender and gender diverse people has been developed in response to the strong desire for increased training. In addition, a co-ordinated response from endocrine societies, fellowship program directors, training providers, healthcare educators and universities in partnership with TGD community members is urgently needed to ensure endocrinologists are confident and competent in being able to provide necessary care for TGD people.

\section{REFERENCES}

1. Hembree WC, Cohen-Kettenis PT, Gooren L, et al. Endocrine Treatment of Gender-Dysphoric/Gender-Incongruent Persons: An Endocrine Society Clinical Practice Guideline. The Journal of clinical endocrinology and metabolism. 2017;102(11):3869-3903.

2. APA APA. Diagnostic and statistical manual of mental disorders (5th ed.). 2013.

3. Dhejne C, Lichtenstein P, Boman M, Johansson AL, Langstrom N, Landen M. Longterm follow-up of transsexual persons undergoing sex reassignment surgery: cohort study in Sweden. PloS one. 2011;6(2):e16885.

4. $\quad$ Flores AR, Herman, J.L., Gates, G.J., \& Brown, T.N.T. . How Many Adults Identify as Transgender in the United States? Los Angeles, CA: The Williams Institute. 2016.

5. Klopfenstein BJ, Kim MS, Krisky CM, Szumowski J, Rooney WD, Purnell JQ. Comparison of $3 \mathrm{~T}$ MRI and CT for the measurement of visceral and subcutaneous adipose tissue in humans. The British journal of radiology. 2012;85(1018):e826-830.

6. Telfer M, Tollit M, Feldman D. Transformation of health-care and legal systems for the transgender population: The need for change in Australia. Journal of paediatrics and child health. 2015;51(11):1051-1053.

7. Cheung AS, Ooi 0 , Leemaqz $S$, et al. Sociodemographic and Clinical Characteristics of Transgender Adults in Australia. Transgender health. 2018;3(1):229-238. 
8. Hyde Z DM, Tilley PJM, McCaul KA, Rooney R, Jancey J. The First Australian National Trans Mental Health Study: Summary of Results. Curtin University. 2014.

9. Smith MK, Mathews B. Treatment for gender dysphoria in children: the new legal, ethical and clinical landscape. The Medical journal of Australia. 2015;202(2):102-104.

10. Strauss P, Cook A, Winter S, Watson V, Wright Toussaint D, Lin A. Associations between negative life experiences and the mental health of trans and gender diverse young people in Australia: findings from Trans Pathways. Psychol Med. 2019:1-10.

11. Bauer GR, Scheim AI, Pyne J, Travers R, Hammond R. Intervenable factors associated with suicide risk in transgender persons: a respondent driven sampling study in Ontario, Canada. BMC public health. 2015;15:525.

12. White Hughto JM, Reisner SL. A Systematic Review of the Effects of Hormone Therapy on Psychological Functioning and Quality of Life in Transgender Individuals. Transgend Health. 2016;1(1):21-31.

13. Erasmus J, Bagga H, Harte F. Assessing patient satisfaction with a multidisciplinary gender dysphoria clinic in Melbourne. Australasian psychiatry: bulletin of Royal Australian and New Zealand College of Psychiatrists. 2015;23(2):158-162.

14. Coleman E BW, Botzer M, Cohen-Kettenis P, DeCuypere G, et al. Standards of Care for the Health of Transsexual, Transgender, and Gender Nonconforming People. The World Professional Association for Transgender Health. 2012.

15. Inder W. Statement from the Endocrine Society of Australia regarding marriage equality and gender issues. Endocrine Society of Australia. 2017.

16. Grant JM ML, Tanis J, Herman JL, Harrison J, Keisling M. National Transgender Discrimination Survey Report on health and health care Findings of a Study by the National Center for Transgender Equality and the National Gay and Lesbian Task Force. 2010.

17. Bradford J, Reisner SL, Honnold JA, Xavier J. Experiences of transgender-related discrimination and implications for health: results from the Virginia Transgender Health Initiative Study. American journal of public health. 2013;103(10):18201829. 
18. Hyde Z DM TP, McCaul KA, Rooney R, Jancey J. . The First Australian National Trans Mental Health Study: Summary of Results. Curtin University. 2014.

19. Davidge-Pitts C, Nippoldt TB, Danoff A, Radziejewski L, Natt N. Transgender Health in Endocrinology: Current Status of Endocrinology Fellowship Programs and Practicing Clinicians. The Journal of clinical endocrinology and metabolism. 2017;102(4):1286-1290.

20. Irwig MS. Transgender Care by Endocrinologists in the United States. Endocrine practice : official journal of the American College of Endocrinology and the American Association of Clinical Endocrinologists. 2016;22(7):832-836.

21. Obedin-Maliver J, Goldsmith ES, Stewart L, et al. Lesbian, gay, bisexual, and transgender-related content in undergraduate medical education. Jama. 2011;306(9):971-977.

22. Grossmann M, Anawalt BD, Wu FC. Clinical practice patterns in the assessment and management of low testosterone in men: an international survey of endocrinologists. Clinical endocrinology. 2015;82(2):234-241.

23. Morrison SD, Dy GW, Chong HJ, et al. Transgender-Related Education in Plastic Surgery and Urology Residency Programs. J Grad Med Educ. 2017;9(2):178-183.

24. Dubin SN, Nolan IT, Streed CG, Jr., Greene RE, Radix AE, Morrison SD. Transgender health care: improving medical students' and residents' training and awareness. Advances in medical education and practice. 2018;9:377-391.

25. Davidge-Pitts CJ, Nippoldt TB, Natt N. Endocrinology fellows' perception of their confidence and skill level in providing transgender healthcare. Endocrine practice: official journal of the American College of Endocrinology and the American Association of Clinical Endocrinologists. 2018;24(12):1038-1042.

26. Schuster MA, Reisner SL, Onorato SE. Beyond Bathrooms--Meeting the Health Needs of Transgender People. N EnglJ Med. 2016;375(2):101-103.

27. Cheung AS, Wynne K, Erasmus J, Murray S, Zajac JD. Position statement on the hormonal management of adult transgender and gender diverse individuals. The Medical journal of Australia. 2019;211(3):127-133.

Table 1:

Survey participant demographics

This article is protected by copyright. All rights reserved 
Male gender

Female gender

Other

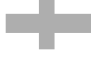

Australian State or Territory of residence

Australian Capital Territory (ACT)

New South Wales (NSW)

Northern Territory (NT)

Queensland

South Australia (SA)

Tasmania

Victoria

Western Australia (WA)

\section{Occupation}

Adult Endocrinologist

Paediatric endocrinologist

Endocrine Trainee

Main place of practice

Hospital-

Tertiary

Hospital Non-tertiary

Private clinic

Other

\section{of practice}

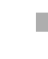

Number of TGD individuals ever seen

None

$1-4$

$5-9$

$10-19$
$21(14.3 \%)$

$50(34.0 \%)$

$97(66.0 \%)$

$0(0 \%)$

$1(0.7 \%)$

$24(16.3 \%)$

$1(0.7 \%)$

$7(4.8 \%)$

$17(11.6 \%)$

$2(1.4 \%)$

$72(49.0 \%)$

$23(15.7 \%)$

$95(64.6 \%)$

$2(1.4 \%)$

$50(34 \%)$

$110(74.8 \%)$

$8(5.4 \%)$

$26(17.7 \%)$

$3(2.0 \%)$

$73(49.6 \%)$

$24(16.3 \%)$

$15(10.2 \%)$

This article is protected by copyright. All rights reserved 
Number of TGD individuals are currently under their care

None

$95(64.6 \%)$

le

$1-4$

$35(23.8 \%)$

2:

5-9

10-19

$4(2.7 \%)$

Con

$>20$

$5(3.4 \%)$

fide

$8(5.4 \%)$

nce

experience

Characteristic

Number (\%)

Management preferences in response to scenario

Prefer not to treat

$1(0.7 \%)$

Refer to a colleague

$80(54.4 \%)$

Consider treating

$29(19.7 \%)$

Feel comfortable treating

$28(19.1 \%)$

Unsure

$8(5.4 \%)$

NA

$1(0.7 \%)$

Confidence in trans medicine compared with other areas in Endocrinology

Performing a consultation

Not at all confident

$37(25.2 \%)$

Less confident

$62(42.2 \%)$

Reasonably confident

$42(28.6 \%)$

More confident

$6(4.1 \%)$

\section{Taking a history}

Not at all confident

$20(13.6 \%)$

Less confident

$57(38.8 \%)$

Reasonably confident

$61(41.5 \%)$

More confident

$8(5.4 \%)$

Commencing cross-sex hormone therapy 
Not at all confident

Less confident

Reasonably confident

More confident

Monitoring cross-sex hormone therapy

Not at all confident

Less confident

Reasonably confident

More confident

Table 3:

Levels of training

\begin{tabular}{llll} 
Training in transgender & $\begin{array}{l}\text { Medical } \\
\text { student } \\
\text { medicine as a: }\end{array}$ & $\begin{array}{l}\text { Endocrine } \\
\text { trainee. } \\
\text { Number (\%) }\end{array}$ & $\begin{array}{l}\text { Qualified } \\
\text { endocrinologist } \\
\text { Number (\%) }\end{array}$ \\
\hline Yes & $2(1.4 \%)$ & $53(36.1 \%)$ & $43(29.3 \%)$ \\
No & $136(92.5 \%)$ & $85(57.8 \%)$ & $59(40.1 \%)$ \\
N/A & $3(2.0 \%)$ & $3(2.0 \%)$ & $39(26.5 \%)$ \\
No answer given & $6(4.1 \%)$ & $6(4.1 \%)$ & $6(4.1 \%)$
\end{tabular}

Characteristic

Number (\%)

Amount of training received in transgender medicine

Too much

$0(0.0 \%)$

Adequate

$18(12.2 \%)$

Not enough

$129(87.8 \%)$

Desire for more training in treating TGD individuals

Yes

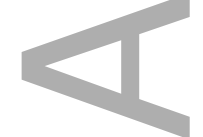

No

$33(90.5 \%)$

$14(9.5 \%)$

Whether relevant Endocrine Society clinical practice guidelines had been read 

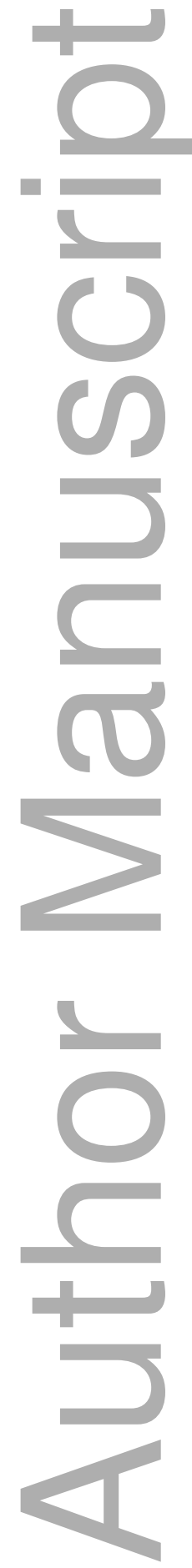


\section{APPENDICES}

APPENDIX 1

Transgender Care Survey: Endocrinologists and Trainees

The purpose of this study

This survey is to help us understand aspects of transgender healthcare and the levels of educations and training for Endocrinologists and Trainees.

Taking part in this study

You must be aged over 18 to take part in this survey. By completing the following survey, you are telling us that understand the purpose of this study, and that results will be used for research purposes. If you do not wish to take part in this project, please do not fill out the survey. All responses are anonymous.

Further information and who to contact

The person you may need to contact will depend on the nature of your query.

Clinical contact person: Dr Ingrid Bretherton PhD Candidate

Telephone 94962486

Email ibretherton@student.unimelb.edu.au

If you have any complaints about any aspect of the project, the way it is being conducted or any questions about being a research participant in general, then you may contact:

\section{Complaints contact person}

Complaints Officer (03) 94964090 or (03) 94963248 Email ethics@austin.org.au

Q1 What is your gender?

$\square$ Male

$\square$ Female

Other (please specify)

Q2 What is your age range? 
$\square$ 30-39

$\square$ 40-49

$\square$ 50-59

$\square$ 60-69

$\square>70$

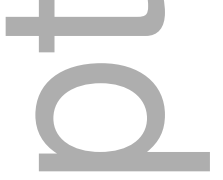

Q3. Which Australian State do you live in?

$\square$ Australian Capital Territory

$\square$ New South Wales

$\square$ Northern Territory

Queensland

$\square$ South Australia

Tasmania

Victoria

$\square$ Western Australia

\section{Q4. What is your occupation?}

$\square$ Adult Endocrinologist

$\square$ Paediatric Endocrinologist

$\square$ Advanced Trainee in Endocrinology

Other (please specify)

Q5. Where is your main place of practice? (where you work the most hours during the week)

$\square$ Tertiary hospital

$\square$ Hospital - non-tertiary Private clinic

Other (please specify)

For the following questions, formal training refers to lectures, tutorials, conference presentations or workshops etc.

Q6. Have you ever attended any training in transgender medicine as a

This article is protected by copyright. All rights reserved 


\section{Medical Student?}

$\square$ Yes

$\square$ No

$\square$ N/A

Endocrinology Advanced Trainee or Medical Officer?

If you are still training, have you received any training to date (excluding today's lecture)?

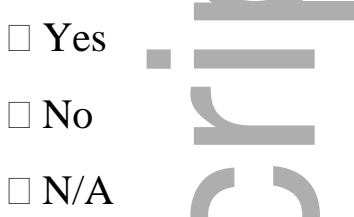

Qualified Endocrinologist?

$\square$ Yes

$\square$ No

$\square$ N/A

Q7. Overall, how would you rate the amount of training you received in transgender medicine?

Too much

$\square$ Adequate

$\square$ Not enough

Q8. Would you like to receive more training in treating trans and gender diverse individuals?

$\square$ No

$\square$ Yes

If yes, how would you prefer this to be delivered? Seminar or Symposium at Conference, Dedicated series of lectures on transgender health, Dinner/Lunch Meeting, Online Resources, Clinical Observation, Peer support groups

Q9. How many trans or gender diverse individuals have you ever seen?

$\square$ None

$1-4$

$\square 5-9$

$10-19$ 
Q10. How many trans or gender diverse individuals are currently under your care?

$\square$ None

$\square 1-4$

$\square$ 5-9

$\square 10-19$

$\square>20$

-

Q11. Have you ever read the Endocrine Society clinical practice guidelines on treatment of transsexual individuals?

Yes

$\square$ No

Q12. Please consider this scenario. You receive a referral from a GP to treat a 30 -year-old birth assigned female who identifies as male and has been formally diagnosed with gender dysphoria by an experienced psychiatrist. They are now seeking testosterone as cross-sex hormone therapy. Would you

Prefer not to treat

$\square$ Refer to a colleague or specialist gender service Consider treating

Feel comfortable treating

$\square$ Unsure

Not applicable - I am a paediatric endocrinologist

Q13. Compared with other areas in Endocrinology, how confident do you feel with the various medical aspects of managing trans and gender diverse patients?

\begin{tabular}{|l|l|l|l|l|}
\hline & $\begin{array}{l}\text { Not at all } \\
\text { confident }\end{array}$ & $\begin{array}{l}\text { Less } \\
\text { confident }\end{array}$ & $\begin{array}{l}\text { Reasonably } \\
\text { confident/the } \\
\text { same }\end{array}$ & $\begin{array}{l}\text { More } \\
\text { confident }\end{array}$ \\
\hline $\begin{array}{l}\text { Performing a consultation with a trans } \\
\text { or gender diverse individual }\end{array}$ & & & & \\
\hline Taking a history from a trans or gender & & & & \\
\hline
\end{tabular}




\begin{tabular}{|l|l|l|l|l|}
\hline diverse individual & & & & \\
\hline Commencing cross-sex hormone & & & & \\
therapy & & & & \\
\hline Monitoring cross-sex hormone therapy & & & & \\
\hline
\end{tabular}

*Q14. Would you find an online resource with Australian-based evidence-based resources beneficial? This would be aimed at assisting endocrinologists, GPs and other health professionals to treat individuals with gender dysphoria including suggested management of hormonal therapies, lists of surgeons, legal resources, available gender clinics etc.

$\square$ Yes

$\square$ No

$\square$ Somewhat

Unsure

*Q15. What other areas (if any) of managing trans or gender diverse individuals would you like training in?

*Q16. Do you have any other comments?

Thank you very much for your responses.

* Questions with few responses or requiring free text answers excluded from analysis

\section{APPENDIX 2}

Table 1.1

Comparison of confidence levels of practitioners when performing a consultation (question 13) who had seen one or more transgender patient compared to those who had seen none (question 9) using Cochran-Armitage test

\begin{tabular}{cccccccc} 
& & & \multicolumn{5}{c}{ Reasonably } \\
Aspect of & No. TGD & Not at all & Less & confident/the & More \\
consultation & individuals & confident. & confident. & same. No. & confident. & Total \\
\hline Performing a & None & $10(48.6 \%)$ & $10(47.6 \%)$ & $1(4.8 \%)$ & $0(0.0 \%)$ & 21 \\
consultation with a & $>=1$ & $27(21.4 \%)$ & $52(41.3 \%)$ & $41(32.5 \%)$ & $6(4.8 \%)$ & 126
\end{tabular}




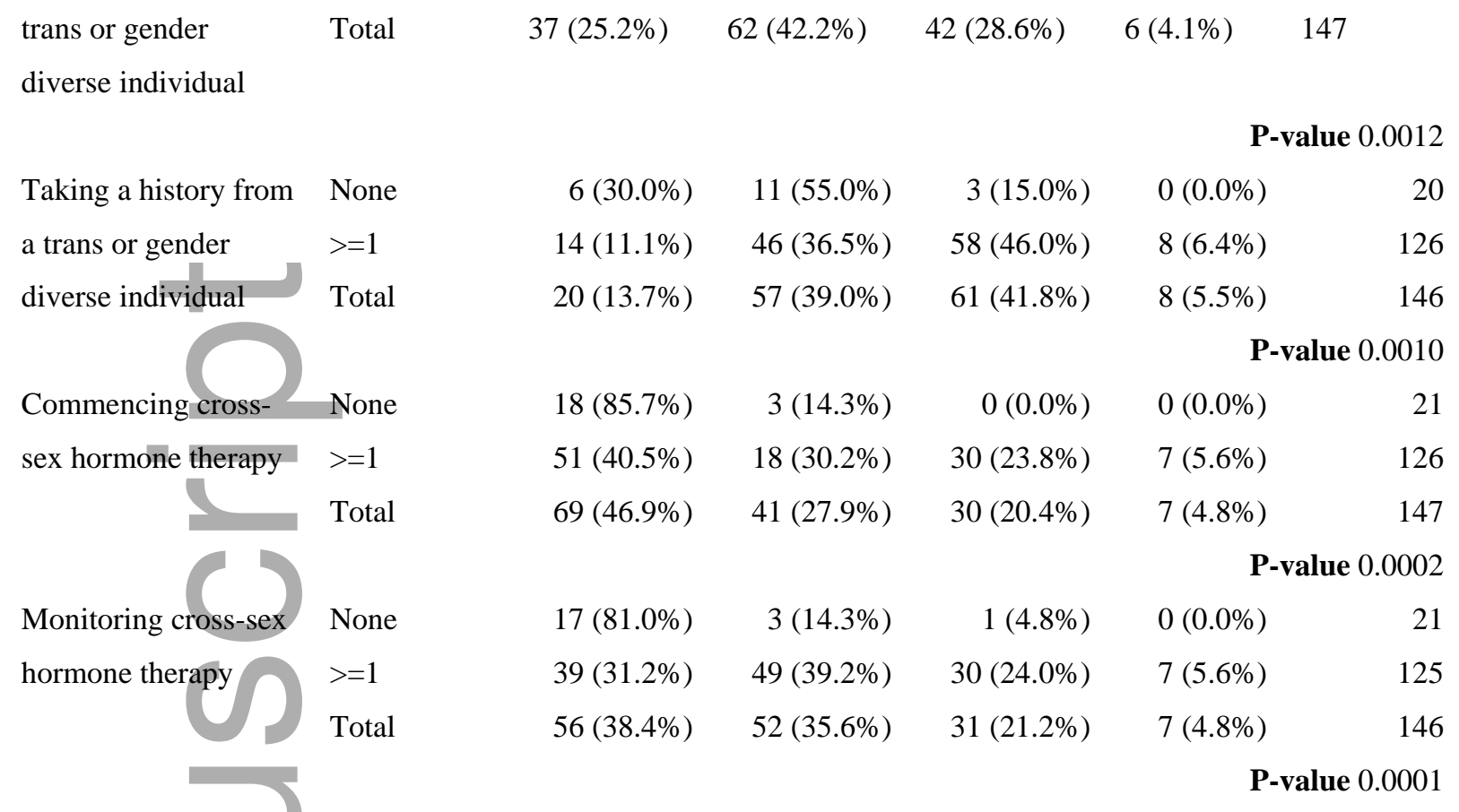

Table 1.2

Comparison of confidence levels of practitioners when performing a consultation (question 13) who had seen one or more transgender patient compared to those who had seen none (question 9) displayed as column wise percentages

\begin{tabular}{|c|c|c|c|c|c|}
\hline Aspect of consultation & $\begin{array}{l}\text { No. TGD } \\
\text { individuals } \\
\text { ever seen }\end{array}$ & $\begin{array}{l}\text { Not at all } \\
\text { confident }\end{array}$ & $\begin{array}{c}\text { Less } \\
\text { confident }\end{array}$ & $\begin{array}{c}\text { Reasonably } \\
\text { confident/the } \\
\text { same }\end{array}$ & $\begin{array}{c}\text { More } \\
\text { confident }\end{array}$ \\
\hline Performing a consultation with & None & $27.0 \%$ & $16.1 \%$ & $2.4 \%$ & $0.0 \%$ \\
\hline a trans or gender diverse & $>=1$ & $73.0 \%$ & $83.9 \%$ & $97.6 \%$ & $100.0 \%$ \\
\hline Taking a history from a trans or & None & $30.0 \%$ & $19.3 \%$ & $4.9 \%$ & $0.0 \%$ \\
\hline gender diverse individual & $>=1$ & $70.0 \%$ & $80.7 \%$ & $95.1 \%$ & $100.0 \%$ \\
\hline Commencing cross-sex & None & $26.1 \%$ & $7.3 \%$ & $0.0 \%$ & $0.0 \%$ \\
\hline hormone therapy & $>=1$ & $73.9 \%$ & $92.7 \%$ & $100.0 \%$ & $100.0 \%$ \\
\hline Monitoring cross-sex hormone & None & $30.4 \%$ & $5.8 \%$ & $3.2 \%$ & $0.0 \%$ \\
\hline therapy & $>=1$ & $69.6 \%$ & $94.2 \%$ & $96.8 \%$ & $100.0 \%$ \\
\hline
\end{tabular}

\section{Table 2.1}


Comparison of confidence levels of practitioners when performing a consultation (question 13 in those who has previously read the relevant Endocrine society guidelines to those who had never read them (question 11) using Cochran-Armitage test

\begin{tabular}{|c|c|c|c|c|c|c|}
\hline $\begin{array}{l}\text { Aspect of } \\
\text { consultation }\end{array}$ & $\begin{array}{l}\text { No. TGD } \\
\text { individuals } \\
\text { ever seen }\end{array}$ & $\begin{array}{l}\text { Not at all } \\
\text { confident. } \\
\text { No. }(\%)\end{array}$ & $\begin{array}{c}\text { Less } \\
\text { confident. } \\
\text { No. }(\%)\end{array}$ & $\begin{array}{l}\text { Reasonably } \\
\text { confident/the } \\
\text { same. No. } \\
(\%)\end{array}$ & $\begin{array}{c}\text { More } \\
\text { confident. } \\
\text { No. }(\%)\end{array}$ & Total \\
\hline Performing a & None & $30(38.0 \%)$ & $36(45.6 \%)$ & $12(15.2 \%)$ & $2(1.3 \%)$ & 79 \\
\hline consultation wit & $>=1$ & $7(10.3 \%)$ & $26(38.2 \%)$ & $30(44.1 \%)$ & $6(7.4 \%)$ & 68 \\
\hline trans or gender & Total & $37(25.2 \%)$ & $62(42.2 \%)$ & $42(28.6 \%)$ & $8(4.1 \%)$ & 147 \\
\hline & & & & & \multicolumn{2}{|c|}{$\mathbf{P}$-value $<0.0001$} \\
\hline Taking a history from & None & $16(20.5 \%)$ & $40(51.3 \%)$ & $20(25.6 \%)$ & $2(2.6 \%)$ & 78 \\
\hline a trans or gender & $>=1$ & $4(5.9 \%)$ & $17(25.0 \%)$ & $41(60.3 \%)$ & $6(8.8 \%)$ & 68 \\
\hline diverse individual & Total & $20(13.7 \%)$ & $57(39.0 \%)$ & $61(41.8 \%)$ & $8(5.5 \%)$ & 146 \\
\hline & & & & & \multicolumn{2}{|c|}{ P-value $<0.0001$} \\
\hline Commencing & None & $51(64.6 \%)$ & $22(27.9 \%)$ & $5(6.3 \%)$ & $1(1.3 \%)$ & 79 \\
\hline sex hormone therap & $>=1$ & $18(26.5 \%)$ & $19(27.9 \%)$ & $25(36.8 \%)$ & $6(8.8 \%)$ & 68 \\
\hline & Total & $69(46.9 \%)$ & $41(27.9 \%)$ & $30(20.4 \%)$ & $7(4.8 \%)$ & 147 \\
\hline & & & & & \multicolumn{2}{|c|}{$\mathbf{P}$-value $<0.0001$} \\
\hline Monitoring cross-sex & None & $44(56.4 \%)$ & $26(33.3 \%)$ & $7(9.0 \%)$ & $1(1.3 \%)$ & 78 \\
\hline hormone therapy & $>=1$ & $12(17.6 \%)$ & $26(38.3 \%)$ & $24(35.3 \%)$ & $6(8.8 \%)$ & 68 \\
\hline & Total & $56(38.4 \%)$ & $52(35.6 \%)$ & $31(21.2 \%)$ & $7(4.8 \%)$ & 146 \\
\hline & & & & & \multicolumn{2}{|c|}{ P-value $<0.0001$} \\
\hline
\end{tabular}

Table 2.2

Comparison of confidence levels of practitioners when performing a consultation (question 13 in those who had previously read the relevant Endocrine society guidelines to those who had never read them (question 11) displayed as column-wise percentages

\begin{tabular}{lllcrr}
\multicolumn{1}{c}{ Aspect of consultation } & No. TGD & & \multicolumn{2}{c}{ Reasonably } \\
& $\begin{array}{c}\text { individuals } \\
\text { ever seen }\end{array}$ & $\begin{array}{c}\text { Not at all } \\
\text { confident }\end{array}$ & $\begin{array}{c}\text { Less } \\
\text { confident }\end{array}$ & $\begin{array}{r}\text { confident/the } \\
\text { same }\end{array}$ & $\begin{array}{c}\text { More } \\
\text { confident }\end{array}$ \\
\hline Performing a consultation with & None & $81.1 \%$ & $58.1 \%$ & $28.6 \%$ & $16.7 \%$ \\
$\begin{array}{l}\text { a trans or gender diverse } \\
\text { individual }\end{array}$ & $>=1$ & $18.9 \%$ & $41.9 \%$ & $71.4 \%$ & $83.3 \%$
\end{tabular}




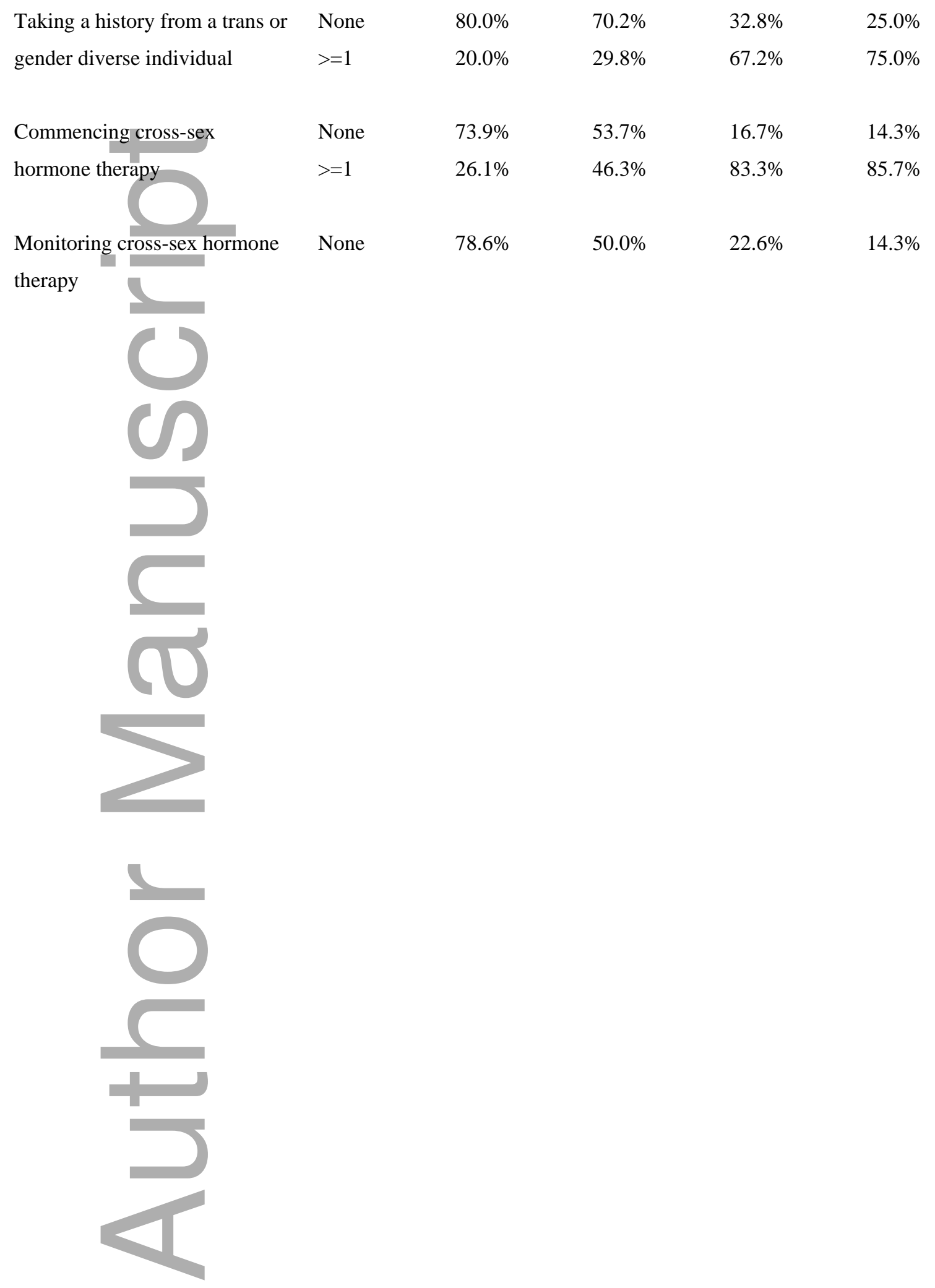




\section{University Library}

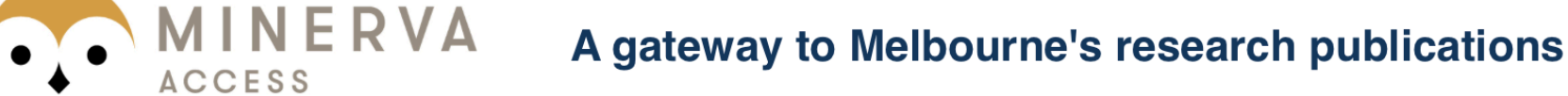

Minerva Access is the Institutional Repository of The University of Melbourne

Author/s:

Bretherton, I;Grossmann, M;Leemaqz, SY;Zajac, JD;Cheung, AS

Title:

Australian endocrinologists need more training in transgender health: A national survey

Date:

2020-01-01

Citation:

Bretherton, I., Grossmann, M., Leemaqz, S. Y., Zajac, J. D. \& Cheung, A. S. (2020).

Australian endocrinologists need more training in transgender health: A national survey. CLINICAL ENDOCRINOLOGY, 92 (3), pp.247-257. https://doi.org/10.1111/cen.14143.

Persistent Link:

http://hdl.handle.net/11343/275228 